\title{
ASSESMENT OF KNOWLEDGE AND ATTTITUDE OF PARENTS REGARDING UNIVERSAL IMMUNIZATION PROGRAMME (UIP)
}

\section{Dr. Ashok Kumar Dhanwal*}

*Nursing Officer, PGIMER \& RMLH, New Delhi, India.

\section{ABSTRACT}

DOI: http://doi.org/10.47211/idcij.2020.v07iws02.002

Immunization is vital; it protects nearly $3 / 4^{\text {th }}$ of children against major childhood illness. There are several diseases which can be easily prevented by timely vaccination as part of routine immunization. India's vaccine deficit has several causes like poorly educated population or lack of awareness among people. Aim; To assess the knowledge and attitude of parents regarding universal immunization programme. To determine the significant association of knowledge and attitude with selected demographic variables and To teach a health education module on UIP of India. Material and methods; an exploratory descriptive survey method was used as a research design. Statistics was accumulated with the aid of convenient sampling method from 500 parents of selected rural areas of Jaipur city. The tool included ten demographic variable and 30 established questions regarding knowledge and attitude on immunization. Descriptive and inferential statistics were used for analysis. Conclusion: The study revealed that the majority of parents have moderate score of knowledge 59.8\% regarding immunization where as $40.2 \%$ have inadequate level of knowledge. It is also depicts that none of them have adequate level of knowledge regarding immunization. And the attitude score calculated that $20.6 \%$ parents have positive attitude towards immunization of under-five children whereas majority of parents $77.4 \%$ have no opinion or don't know regarding child immunization and only $2 \%$ parents have negative attitude towards child immunization. there is significant association between the score level of knowledge and selected demographic variables like (age, religion, monthly income, education, type of family, source of acquiring knowledge and status of immunization). There is no significance association between the level of knowledge scores and other demographic variables like (sex, occupation and number of under-five year children) The calculated chi-square values were less than the table value at the 0.05 level of significance. There is significance association between the score level of attitude and demographic variables (age, numbers of under-five children in family, religion, occupation, monthly income and education). There is no significance association between the level of scores and other demographic variables (sex, type of family, source of acquiring knowledge and status of immunization) The calculated chi-square values were less than the table value at the 0.05 level of significance.

Key Words: Knowledge, attitude, universal immunization programme, parents.

\section{ABOUT AUTHOR:}

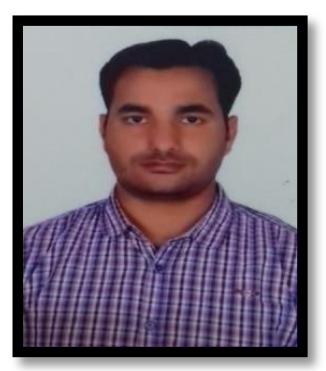

Author, Dr. Ashok Kumar Dhanwal is a Ph.D. in Nursing. At present he is working as the nursing officer in PGIMER \& RMLH. He has presented research papers in various conferences and workshops. 


\section{INTRODUCTION}

Immunization is vital; it protects nearly $3 / 4^{\text {th }}$ of children against major childhood illness. There are several diseases which can be easily prevented by timely vaccination as part of routine immunization. India's vaccine deficit has several causes like poorly educated population or lack of awareness among people. . Immunization is one of the cost effective interventions to prevent a series of major illness. Therefore, Parental decisions regarding immunization are very important for increasing the immunization rate and compliance and for decreasing any possible immunization errors. Parents' knowledge and practices regarding immunization are the major factors that contribute to their vaccination decisions. Children in India continue to lose their lives to vaccine-preventable diseases such as measles, which remains the bigger killer. Tetanus in newborn also remains a problem. Diarrheal remains the second major cause of death among children, after respiratory-tract infections. Unhygienic practices and unsafe drinking water are some of its main causes .Immunization saves more than 3 million lives worldwide each year, and it saves millions more from suffering illness and lifelong disability (WHO estimate, 2009)

\section{OBJECTIVES:-}

1. To assess the knowledge and attitude of parents regarding Universal immunization Programme.

2. To find out the relation between knowledge and attitude of parents regarding Universal immunization Programme.

3. To determine the significant association of knowledge and attitude with selected demographic variables.

4. To distribute and teach a health education module on Universal immunization Programme.

\section{HYPOTHESIS}

H1: There will be significant relationship between knowledge and attitude of parents of under five children regarding immunization.

H2; There will be a significant association of the knowledge and attitude of parents with demographic variable.

\section{MATERIAL AND METHODS}

\section{Research design}

An exploratory descriptive survey method was used as a research design.

\section{Setting of the study:-}

Setting refers to the physical locations in this study data collected from the selected rural areas (Vatica and Goner village) in Jaipur city. The selection of rural areas was done on the geographic proximity, feasibility of conducting study and availability of sample.

\section{Population}

Population includes "all possible elements that could be included in research." The requirement of defining population for a research project arises from the need to which the results of the study can be applied. In this study, the population includes parents of under-five children of selected rural areas of Jaipur.

\section{Sample}

A sample was a small portion of the population selected for observation, analysis and the members of the sample are study subjects. In this study the samples are parents (mother and father) of under-five children at selected rural areas of Jaipur.

\section{Sample size}

The total study sample consists of 500 mothers and fathers of under- five year children.

\section{Sampling technique}

Sampling technique is the procedure that the researcher adopts in selecting the samples. For this study convenient sampling technique was adopted.

\section{RESULTS}

\section{1, DISTRIBUTION OF SAMPLE ACCORDING TO DEMOGRAPHIC VARIABLES:}

The age of the samples ranged from 18-36 years and above, in that the majority of samples (43\%) were in 2630 year age group. In this study fathers (51\%) \& mother (49\%) of less than five year children were participated in the present study. A majority of parents have two under five year children (66\%) in their family. In This study 


\section{ARTICLES}

that majority of parents belong to Hindu religion (71\%) and most of the parents (45\%) educated up to eight classes. A high percentage of mother were house wife (32\%) and father of under five children were doing business(22\%), servant(21\%) or doing other occupation like farmer(26\%). The above table also shows that majority of parents belongs to joint family (64\%) where as $33 \%$ parents belonging to nuclear family. Majority of parents (49\%) monthly income ranging between 6500 to 14000 per month.

This table also depicts that (48\%) parents acquiring knowledge regarding immunization from mass media. Out of 863 under five children, majority of under five year children (44\%) were partially immunized and none of children were fully immunized as per universal immunization schedule.

2, LEVEL OF KNOWLEDGE OF PARENTS OF UNDERFIVE CHILDREN REGARDING UNIVERSAL IMMUNIZATION PROGRAMME :

\begin{tabular}{|l|l|l|}
\hline CRITERIA MEASURE OF KNOWLEDGE SCORE \\
\hline Category Score & Percentage & Frequency \\
\hline Adequate(17-23) & $0.0 \%$ & 0 \\
\hline Moderate(9-16) & $59.8 \%$ & 299 \\
\hline Inadequate(0-8) & $40.2 \%$ & 201 \\
\hline
\end{tabular}

Maximum Score $=23$ Minimum Score $=0$

\section{3, LEVEL OF ATTITUDE SCORE OF PARENTS OF UNDERFIVE CHILDREN REGARDING UNIVERSAL} IMMUNIZATION PROGRAMME:

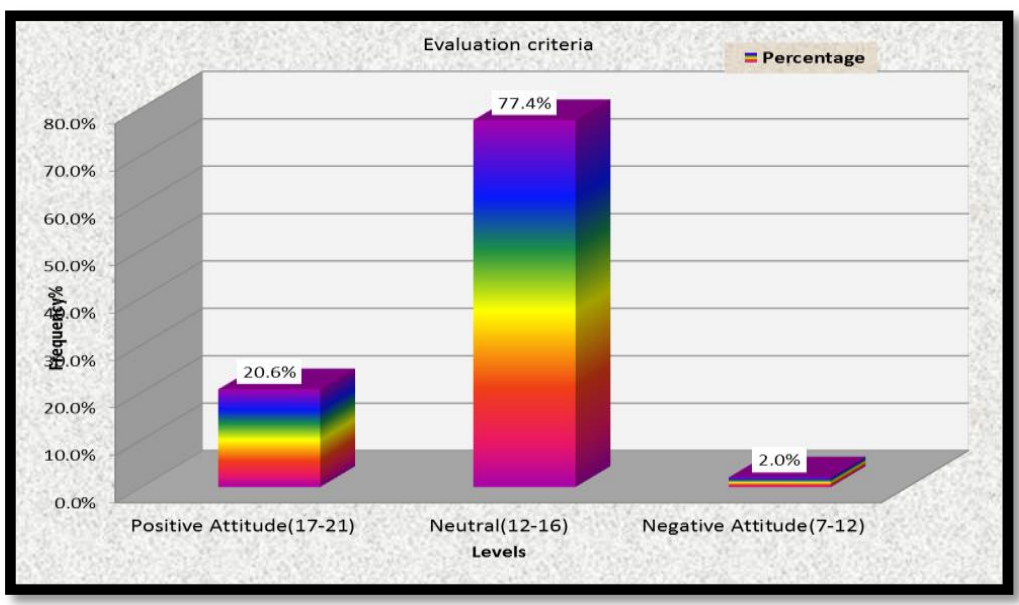

4, CO-RELATION BETWEEN KNOWLEDGE AND ATTITUDE OF PARENTS REGARDING UNIVERSAL IMMUNIZATION PROGRAMME:

\begin{tabular}{|c|c|c|}
\hline \multirow{2}{*}{$\begin{array}{c}\text { Pearson's } \\
\text { Correlation }\end{array}$} & $\begin{array}{c}|c| \\
\text { KNOWLEDGE } \\
\text { Score }\end{array}$ & $\begin{array}{c}\text { ATTITUDE } \\
\text { Score }\end{array}$ \\
\hline Mean & 9.13 & 14.85 \\
\hline SD & 2.093 & 1.810 \\
\hline $\mathrm{N}$ & \multicolumn{2}{|c|}{500} \\
\hline Correlation & \multicolumn{2}{|c|}{-0.032} \\
\hline Table Value & 0.088 \\
\hline P Value & \multicolumn{2}{|c|}{0.471} \\
\hline Result & Not Significant \\
\hline
\end{tabular}




\section{5, THE ASSOCIATION BETWEEN KNOWLEDGE SCORE AND SELECTED DEMOGRAPHIC VARIABLES:}

The association between the level of knowledge score and socio demographic variable has been studied here. Based on the 3rd objectives used to Chi-square test for determine association between the level of knowledge and selected demographic variables. The Chi-square value shows that there is significant association between the score level of knowledge and selected demographic variables like ( age, religion, monthly income, education, type of family, source of acquiring knowledge and status of immunization). There is no significance association between the level of scores and other demographic variables like (sex, occupation and number of under five year children) The calculated chi-square values were less than the table value at the 0.05 level of significance.

\section{6, THE ASSOCIATION BETWEEN ATTITUDE SCORE AND SELECTED DEMOGRAPHIC VARIABLES:}

Based on the 3rd objectives used to Chi-square test used to associate the level of knowledge and selected demographic variables. The Chi-square value shows that there is significance association between the attitude score level and demographic variables (age, numbers of under five children in family, religion, occupation, monthly income and education). There is no significance association between the level of attitude scores and other demographic variables (sex, type of family, source of acquiring knowledge and status of immunization) The calculated chi-square values were less than the table value at the 0.05 level of significance.

\section{CONCLUSION}

1. The majority of parents have moderate score of knowledge (59.8\%) regarding immunization where as $40.2 \%$ have inadequate level of knowledge. It is also depicts that none of them have adequate level of knowledge regarding immunization.

2. The attitude score calculated that $20.6 \%$ have positive attitude towards immunization of under five children where as majority of parents $\mathbf{7 7 . 4 \%}$ have no opinion or don't know regarding child immunization, It may be due to lack of education among parents. and only $2 \%$ parents have negative attitude towards Universal immunization programme.

3. For improving the knowledge, health education module on UIP distributed to each family and explains about UIP.

\section{IMPLICATIONS}

Nurses' focus should be on education and on interventions. Nurses are participate in various setting in different ways.

Academic: Nurse Educators can use her knowledge to help nursing student to have adequate knowledge so they will be enable to aware the community people regarding immunization and conduct research study on immunization in different ways.

Paediatrics: Nurses can utilize the knowledge in paediatric department like (weekly immunization day at paediatric OPD) motivate the parents regarding importance of immunization.

Maternity: Maternity nurses are in a position to offer information to parents who are unaware regarding immunization.

Community: Nurses is the key member to spread information regarding immunization. She can conduct door to door visit and aware the parents regarding immunization simultaneously she can identified the children who are not immunized against six vaccine preventable disease. And also she can find out the reasons behind it. So that appropriate action can be taken.

Primary Care: Even nurses in adult focused practice settings can use the knowledge to advice parents whose children or grandchildren may be at risk.

\section{RECOMMENDATIONS}

- A similar study can be conducted with large sample size to determine the knowledge, attitude and practice regarding Immunisation.

- A similar study can be done on correlation of knowledge and practice regarding immunization in selected rural areas.

- A comparative study can be done among rural and urban areas on a large scale. 


\section{ARTICLES}

\section{REFERENCES}

1. Gellin B, MaibachE, Marcuse, (2014) .Do parents understand immunizations? A national telephone survey.Paediatrics. 106(5): 1097-1102. Doi;10.1512

2. Ritvo p. et al.(2013). A Canadian national survey of attitude and knowledge regarding preventive vaccines (1);3

3. Sporton R. Francis (2014). Choosing not to immunize are parents making informed decisions? Fampract , 18(2): 181-188

4. Richard, a. Sheridan, j.(2012). Reasons for delayed compliance with the childhood vaccination schedule j. Public health 23(3) 315-317.

5. Jamil K, Bhuiya A, Streatfield K, Chakrabarty (2013) .National Coverage Evaluation Survey.

6. Expanded Program on Immunization (2006). National Coverage Evaluation Survey Report. Dhaka: Ministry of Health and Family Welfare (http://www.who.int/immunization)

7. National Institute of Population Research and Training (NIPORT). (June 2013). Demographic and Health Survey . 14(1):149-58.

8. Jamil K, Bhuiya A, Streatfield K, Chakrabarty N. (2005). The immunization program in Bangladesh: impressive gains in coverage, but gaps remain. Health Policy and Planning 14(1):49-58.

9. Uddin J, Ashraf A, Sirajuddin AKM, Alam M, Tunon C.(2012) Incorporation of community's voice into Health and Population Sector Program of Bangladesh for its transparency and accountability. Dhaka: ICDDR, B,148-154

10. Delany I, Rappuoli R, De Gregorio E.(2014). Vaccines for the 21st century. EMBO; 6:708-20. 